\title{
Perspectives on Sexuality Among Patients with Hypopituitarism: Broadening the Medical Focus on Sexual Function to Include Sexual Wellbeing
}

\author{
Lisen Dellenborg ${ }^{1,2}$ (D) Jenny Tiberg Persson ${ }^{3}$ Eva Jakobsson Ung ${ }^{1,2,3}$. \\ Gudmundur Johannsson ${ }^{3,4}$ - Ann-Charlotte Olofsson ${ }^{1,3} \cdot$ Ida Björkman $^{1,2}$
}

Published online: 17 March 2020

(C) The Author(s) 2020

\begin{abstract}
Hypopituitarism means a partial or complete inability to produce pituitary hormones, including those regulating gonadal function. The condition therefore leads to hormone deficiencies that may affect sexuality in various ways. This study aimed to explore patients' own experiences of hypopituitarism in relation to sexuality, and it is based on interviews with 19 men and women. A qualitative methodology inspired by Gadamer's philosophical hermeneutics was used. Analysis revealed that current healthcare practices, which focus primarily on sexual functioning, fail to address patients' existential concerns about loneliness, loving relationships and selfhood. Another important finding was that women felt that their sexual functioning and wellbeing tended to go unnoticed, while men said that healthcare professionals focused mainly on erectile function rather than problems with sexual wellbeing. Cultural and gender norms were apparent in these healthcare interactions, and proactive efforts to improve awareness is required in order to improve the quality of care provided to these patients. Healthcare professionals need time, space and support for reflection so that they may enhance their knowledge about the complexity of sexuality and discuss the results of research into hormone replacement in men and women. They also need support to develop critical awareness of how gendered norms about sexuality may negatively affect the care provided to persons with hypopituitarism.
\end{abstract}

Keywords Altered sexuality · Sexual function/wellbeing · Hormone deficiency · Patients' experiences $\cdot$ Gender $\cdot$ Normativity $\cdot$ Healthcare encounters

\section{Introduction}

Hypopituitarism is a condition caused by various diseases in the hypothalamic region of the brain. Hypopituitarism may be partial or complete and leads to loss of gonadotropins, which regulate gonadal function in both men and women. This in turn results in reduction or complete loss of androgens and estrogens and, consequently, infertility. The pituitary

Lisen Dellenborg

lisen.dellenborg@gu.se

Extended author information available on the last page of the article 
gland is a master gland situated at the base of the brain that regulates growth, metabolism and fertility through seven endocrine systems. The gland produces and secretes growth hormone, prolactin and hormones that regulate the function of the gonads, the thyroid gland and the adrenal cortex. Gonadal hormones, such as estrogen, progesterone and testosterone are "multi-site chemical growth regulators" that are necessary for functioning of a number of organs throughout the body regardless of gender; the levels of these hormones vary according to gender and age though their chemical structure is constant [1]. The conventional use of the term "sex hormones" to refer to them may therefore be questioned [2, p. 147]. In women, physical reactions related to sexual arousal and orgasm depend on the effects of estrogen, while libido is primarily regulated by testosterone [1]. Miller et al. [3] establish that women with complete hypopituitarism are severely androgen deficient.

In hypopituitarism, the loss of pituitary function is most commonly due to benign tumors [4]. Hypopituitarism in women of child-bearing age results in loss of gonadal function, estrogen deficiency and amenorrhea, and the lack of androgens results in reduced libido, sexual receptivity and pleasure. Signs of testosterone deficiency in men may include reduced libido, erectile problems and loss of body hair. Other symptoms, in both men and women, include impaired wellbeing, lack of energy, motivation and initiative, mental fatigue and emotional reactivity, social isolation, anxiety, sexual problems, decreased physical activity, poor body image, loss of self-confidence, depression, and poor concentration and memory $[4,5]$. This group of patients also has an increased risk of cardiovascular disease and osteoporosis [4, 6, 7]. Findings suggest that women with hypopituitarism may be at greater risk of abdominal obesity, osteopenia and poor quality of life than men if severe androgen deficiency goes untreated [8].

In the case of complete hypopituitarism, hormone replacement therapy includes daily administration of hydrocortisone, thyroxine, growth hormone and gonadal steroids. Androgen deficiency necessitates testosterone replacement in men, while a combination of estrogen and progesterone is usually used in pre-menopausal women to mimic the normal menstrual cycle. Gonadotropin treatment induces ovulation and fertility in women with hypopituitarism [9]. Once a woman has reached the estimated mean age of menopause, estrogen replacement is usually discontinued [4]. Research on the hormonal treatment of women shows that it is complicated [10]. Androgen replacement may have androgenizing effects on the skin and axillary and pubic hair but may increase alertness, stamina, initiative and libido $[8,11]$.

\section{Sexuality and Living with a Chronic Disorder}

Chronic disorders of this kind and their treatment commonly affect sexuality in one or all of three ways: directly, indirectly or iatrogenically [12]. Direct effects of hypopituitarism and its treatment are to be expected since the disorder changes the patient's hormonal balance [4]. Pain or fatigue caused by the disorder may also indirectly affect the patient's sexuality [12]. Iatrogenic effects are the unintended side effects of medication and these may be temporary or permanent. Disturbances in sexual functioning are usually referred to as sexual dysfunction while impaired sexual wellbeing is referred by terms such as sexual problems or concerns [12]. Research has shown that the deficiency of hormones found in hypopituitarism results in both sexual dysfunction and other sexual problems [4]. Healthcare research and practice have both been criticized for focusing narrowly on sexual functioning while overlooking sexual wellbeing in this group [12-14]. However, no studies have been carried out on the patients' own perspectives on their sexuality. 


\section{Sexuality and the Interpretative Prerogative of Medicine}

Sexuality is a complex, multifaceted phenomenon. The right to control one's health and body in relation to sexuality and reproduction is recognized by the World Health Organization as a basic human right [15]. However, a predominantly medicalized understanding of sexuality has long prevailed within the healthcare sciences and sexology [16]. This medical perspective has been criticized for ignoring sexual wellbeing [17] and leading to a medicalization of sexuality. Verschuren et al. [12] have designed a conceptual framework for understanding sexuality in the context of a chronic disorder that identifies medical factors as part of a broader spectrum of problems. Their framework includes biological, psychological, relational and socio-cultural factors and it makes an important distinction between sexual functioning and sexual wellbeing. They relate sexual functioning to "performance standards", such as sexual desire, sexual arousal (e.g. erection, vaginal lubrication) and orgasm. By contrast, they regard sexual wellbeing as referring to a person's own experience of their sexuality in their relationships and in daily life [12]. Cleary and Hegarty [13] further divide sexual wellbeing into sexual relationships and sexual self-conception. Both Verschuren et al.'s and Cleary and Hegarty's frameworks are holistic and are in line with the WHO's [15] definition of sexuality. They note that changes to one features of a person's sexuality will have repercussions for others since they are all interrelated. In other words, sexual functioning, sexual selfconception and sexual relationships are all equally important in a person's sexual health.

\section{The Complexity of Sexuality and Normativity}

From a social constructivist point of view, sexuality is understood as a social, cultural and historical phenomenon. While human sexual physiology is universal, its triggers and the meanings ascribed to it vary according to time and place. People engage in the construction of sexuality in particular social, cultural and historical contexts and this process is related to power differentials, in which factors such as heteronormativity, gender order, social class, age and ability may all play a role [18-22]. Social norms prescribe with whom, when and how people should engage with one another sexually [23-26]. Gender and sexuality are typically shaped and upheld according to the norm of heterosexuality, which is frequently assumed to be 'natural' and 'normal', with men and women differing from and complementing each other [18, 20]. Kulick and Rydström [27] argue that people living with disabilities tend to suffer from a failure by society and its care institutions to defend their right to a sexual life and that this is due to normative understandings of sexuality and disability. Kulick and Rydström [27, p. 268] note that there are strong norms about sexuality being a private matter, and this can be a problem since it awards responsibility to the individual to manage their sexuality by themselves "regardless of their ability to do so".

\section{Aim}

The aim of the present study was to explore perspectives of patients with hypopituitarism on sexuality. 


\section{Method}

\section{Participants}

Using a purposive sampling strategy, 42 patients with pituitary deficiency from a department of endocrinology at a university hospital in Sweden were asked if they would like to participate in the study. Nineteen (12 men and 7 women) agreed to participate. They were suffering from deficiency in growth hormone, thyroid hormone androgens or estrogens, or from reduced levels of all pituitary hormones. The mean age was 57 (range, 37-77) years. Seventeen of them were living with a partner while two lived alone and had no partner. Sixteen had children, twelve were in employment, while seven were retired, four of them, recently.

\section{Data Collection}

Data was collected using semi-structured interviews. The interviewees were encouraged to reflect upon how sexuality related to living with hypopituitarism. This approach was designed to elicit and engage with the participants' experiences in order to enhance our understanding of them [28]. The interviews were performed between October 2011 and April 2012 by three of the co- authors (JPT, EJU, ACO), who are all Registered Nurses (RNs), and two of them (JPT, ACO) had experience of caring for patients with hypopituitarism. The conversations were tape recorded and transcribed verbatim. All authors contributed to the study conception and design. The main analysis was made by LD and IB, and in a preliminary first version by EJU, JPT and ACO. All authors participated in the interpretation of analysis and commented on previous versions of the manuscript. All authors read and approved the final manuscript.

\section{Methodology}

A hermeneutic approach was selected [28, 29]. This approach recognizes that human experience is historically shaped and that our horizons of meaning arise in relation to a particular time and place-our understanding of the world is therefore always from a certain perspective or 'horizon'. However, this horizon is constantly changing and expanding as new experiences are gained. Expansion of the horizon takes place through a process referred to as the hermeneutic circle. This describes the circular movement between: (1) the horizon of the interpreter and that of the subject who is to be understood; (2) the meaning of the parts and the whole of the phenomenon that is to be interpreted. The goal of a hermeneutic act is the "fusion of horizons". This requires that the researcher questions their own preunderstanding and is open to the other's "truth claims". This process may however become a vicious circle if un-questioned pre-understandings and prejudices are permitted to guide interpretation of the 'other' [29]. Inspired by Gadamer's philosophical ideas, Fleming et al. [28] suggest a research process comprising five stages: (1) deciding on a research question; (2) identifying pre-understandings; (3) gaining understanding through dialogue with participants; (4) gaining understanding through dialogue with text and (5) establishing trustworthiness.

Following Fleming et al. [28] we strived to formulate research questions true to the aims of interpretive hermeneutics, that maintain internal consistency and add to the knowledge base. The research questions in our study were: "What is the impact of hypopituitarism on 
sexuality from the patient's perspective?"; "What is the meaning of sexuality for people living with hypopituitarism?" and "What kind of information and support do patients need from healthcare professionals in relation to sexual issues?" We recognize that understanding is gained through personal involvement in a reciprocal interpretive process and that the researcher can never disassociate themselves from their own historical background.

\section{Data Analysis}

An important element in the analysis was therefore identification of the authors' preconceptions about sexuality in general and about caring for people with hypopituitarism. This was achieved through ongoing reflection in conversations between the co-authors [28]. The first author's (LD) anthropological training and knowledge in ethnographic methodology $[30,31]$ was particularly valuable, and it supported the authors in becoming clearer about the interpretive process, in particular concerning preconceptions about sexuality, gender and power relations.

The process of gaining understanding followed the four steps outlined by Fleming et al. [28]. Since Fleming et al.'s notion of dialogue refers to the exchange between not only researcher and participant but also between researcher and text, the authors listened to the tapes several times and then read the entire transcriptions in order to acquire a sense of the entirety. The authors took notes while listening and reading and then wrote a summary of basic meanings of the texts. The next step in analysing the transcriptions involved looking at the whole, then the parts, and then the whole again [29]. During this stage, themes were drawn up to describe the participants' experiences of sexuality in relation to hypopituitarism. The researchers continually considered how their pre-understandings were altered as they became increasingly aware of these themes, and they then rearranged and renamed them accordingly. The final step involved identifying passages in the transcriptions that illustrated shared understandings between the researchers and participants. These analytical stages were not conducted in chronological sequence, but took place in a back-and-forth manner, as described in hermeneutics.

\section{Validity, Reliability and Rigor}

Guidelines provided by Whittemore et al. [32] were used to ensure the rigor and reliability of this study. Firstly, notes were taken about the research process in order to document how understandings evolved during the process of analysis. Furthermore, efforts were made to remain true to what the participants meant by using verbatim quotations. Finally, we made every effort to ensure that the authors were aware that their understanding emerged through personal involvement in a reciprocal interpretive process [28]. Analysis was performed through in-depth comparison of the interviews and in numerous discussions and dialogue between the authors in order to achieve the most reasonable interpretation of the texts.

\section{Ethical Considerations}

This study was carried out in accordance with the Declaration of Helsinki and with approval from the Regional Ethical Review Board of the University of Gothenburg (No. 273-11). Participants were informed about the purpose of the study. They were informed of their right to withdraw at any time without explanation, and that their decision about 
whether or not to participate would in no way influence the care they would receive. The researcher informed them about the interview procedure and explained that interviews would be tape-recorded and transcribed. The researcher stressed to all participants that any identifying details would be excluded from the material to ensure anonymity and confidentiality. Both verbal and written consent were obtained from participants at the time of the interview.

\section{Findings}

The main finding in this study was that hypopituitarism alters sexuality in unsettling ways. Interviewees explained that their condition and the treatments affected their sexuality in various ways. They experienced fatigue, changes in sexual desire and a reduced drive to take initiative. On a more profound level, they also described how the condition affected the way in which they understood their relation to themselves and partners. The loss of sexual desire had a generally debilitating effect on their lust for life and sometimes brought feelings of loss of self. They described sexuality as an important means of communicating love and as a necessary part of initiating new romantic relationships. Hypopituitarism thus impacted heavily on these people's self-perception and intimate relationships. Furthermore, the social silence surrounding sexuality in general made it difficult for them to communicate with others about their experiences, and they often felt alone with their distress. All participants, regardless of their age or physical or social situation, worried about what they referred to as being 'normal'.

Below, we describe five interwoven ways in which these patients experienced unsettling alterations in their sexuality: feelings of loss and sadness, differences in treatment offered according to the patient's gender, the importance of sex in initiating a new romantic relationship, divergences between male and female sexuality and the silence surrounding sexuality that leaves individuals struggling alone with questions about normality.

\section{Feelings of Loss and Sadness}

The participants described experiences of their sexual desire being diminished or even completely "extinguished". One man described how he had stopped noticing women altogether until he received treatment, whereupon, he said, he re-discovered "women's existence". Both men and women said that the loss of sexual desire and activity caused them sadness.

I think it's [sex] important, really important. I went without [sex] for 6 months prior to my diagnosis. If you don't have any sexual drive or lust, you've got nothing. [63-year-old man]

Few of the women made a connection between their diagnosis and reduced libido. Nor did the female interviewees claim that reduced libido impacted as much on their overall wellbeing as the male interviewees did. Yet, sadness about loss of sexual desire was present in their narratives:

After the operation and all the medication... it's difficult to describe how I feel... it's difficult to imagine that having sex would be enjoyable... it feels as though that side of me has been eliminated ... I think that's a pity. (38-year-old woman] 
Paralyzing fatigue and lack of drive are symptoms related to this disorder and they may hinder sexual activity even when libido is unaffected. One man explained that he could not bring himself to take the initiative in sexual contact even though he felt desire:

Sometimes I lie in bed and I'm turned on but I can't make myself take the initiative, that little initial cuddling... [77-year-old man]

Women described similar problems:

I take the initiative sometimes, although I'm not that interested. But I do it so that we will both feel better. Once we're having sex, I enjoy it but it's a little difficult to get started and take that first step. [55-year-old woman]

Sometimes I'm very tired, but if your partner still wants to, well yes, and then it can be really good ... or alright... it's a bit slow in the beginning but then it gets going... the lack of drive to take initiative is something I live with all the time, in other activities too... [37-year-old woman]

Another sign of this disorder is weight gain, and this too influenced self-image and sexual relationships, especially for women. Some of the women described how gaining weight made them feel uncomfortable with their own body. They said that feeling comfortable with one's body, feeling sexy and attractive were important for being able to feel sexual desire for someone else. The men spoke of weight gain more in terms of reduced physical capacity and stamina, which could impact negatively upon their sexuality.

Self-perception was sometimes negatively influenced by the disorder in more pervasive ways. A woman described that her illness, which started before puberty, had complicated her self-perception and identity as a woman:

I never got my period... and I had sexual problems as a teenager. In part, I think it was because I felt that I was different... So, I think that contributed towards complicating my identity as a woman... Sexuality is important and it means a lot for relationships and for my sense of self as a woman. But I never felt like a normal woman. [57-year-old woman]

\section{Gender Differences in Treatment}

For men, medical treatment clearly increased sexual function and desire. They described this experience positively although it could sometimes feel overwhelming after having had no libido before treatment. One participant described this dramatic change in the following words:

When I had my first injection [testosterone treatment], I asked the doctor: 'Will this work?' He told me that another patient's wife had called and asked: 'How can I stop him!' That happened to us as well. It was like I was making up for lost time. I was like, well, a rabbit. I didn't get it [an orgasm] every time though. I was shaking every time I saw a woman's bike. That got me going. Luckily, that has changed now. [63-year-old man]

As is evident in this quote, although libido might increase after treatment, there could still be wide fluctuations in sexual function and experience. Problems with ejaculation and experiencing orgasm could persist. The return of sexual desire after hormone replacement clearly had a positive effect on the person's whole existence and thirst for life. One man described how his first testosterone treatment affected him thus: 
When I had my first testosterone shot, I noticed something very important about sexuality. Normal testosterone levels are incredibly important to one's complete sense of wellbeing. It is a misconception that if you have testosterone you're going to be great in bed, because that is the least important part. Your whole sense of lust for life and general vitality totally relies on it. I really felt that and that's really amazing. [77-year-old man]

Concerning sexual function after becoming ill with hypopituitarism, women had similar experiences to men. They lost interest in sex and experienced less sexual satisfaction. However, the effects of hormone replacement therapy upon their sexual functioning varied. None of the women interviewed expressed such powerful feelings of happiness in relation to the treatment. Some had been treated with estrogen, sometimes in combination with androgens. One woman found that her vaginal lubrication increased and her sexual functioning therefore improved. Another woman said she believed that estrogen amplified sexual desire:

I'm on estrogen but they wanted me to quit taking it since I'm so old now. I am really scared to do that because I don't know how it will affect my sexuality. I could try without it but I'm too scared. It [sexual desire] is so important to me so I'm not ready to risk it. [58-year-old woman]

Significantly, no healthcare provider had discussed matters relating to libido with the women. This meant that few of the women had received treatment to improve their sexual desire, or their treatment had not been assessed on these grounds.

\section{Sex is a Requirement for Initiating New Romantic Relationships}

Both men and women stressed that sexual activity, desire and satisfaction were essential to a well-functioning and 'normal' romantic relationship. They linked sexuality to love, affection, intimacy and union and they described it as an important means of connecting to one's partner, expressing and receiving love and appreciation.

Sex is a union between two people, for me personally, between my husband and me. It is a union that includes affection, communion and the unification of two bodies. [71-year-old woman]

Feeling sexual desire and being engaged in an active sexual relationship were linked to identity and self-esteem. Interviewees said this confirmed that one was "good enough". Low sexual drive had even made some women decide to live without a partner since they considered sex to be prerequisite to a romantic relationship. They believed that sexual intimacy was essential to establishing a relationship and they could not imagine finding a man willing to accept a love relationship without sex. Men also believed that the ability to offer sex was a requirement for being able to enter into new romantic relationships:

When you enter a new relationship in your $60 \mathrm{~s}$, it's incredibly important to be able to offer sex as a part of the relationship. That's what I think anyway. It depends on the partner but I think you are kind of uninteresting if you can't, that's what I think. [75-year-old man]

However, interviewees also claimed that long-term loving relationships could develop even without sex, especially if the couple was ageing together or if illness prevented one of them from engaging in sexual activity. Both men and women pointed out that under such 
conditions, a couple might find other ways to communicate love and union, and that it was physical closeness that mattered most to them.

\section{Male and Female Sexuality as Divergent}

On one hand, men as well as women expressed the importance of physical closeness. On the other, there was a tendency among the interviewees to perceive sexuality as varying according to gender. Women stressed the importance of closeness, hugs, kisses, smiles and a generally warm atmosphere over sexual intercourse, and they said that for them, sexual relations were about feeling secure in an established loving relationship:

... I would never go to the pub and look for someone just for sex or have a short relationship just for sex. I never have, and have never been interested. To me, it is important to have a steady relationship before [engaging in sexual activity]. But there is perhaps a difference between men and women... Or no, that's another myth! It does not depend on what gender you are, but how you are as a person. All people have needs, but they differ depending on how they are as a person. But to me it is important that the relationship is steady, that I can trust the person.... [40-year-old woman]

By contrast, the men described aspects of sexuality, such as feelings of attraction, sexual arousal, sexual triggers and excitement as not necessarily linked to intimate relationships and love. They talked about other women than their partner as triggering sexual desire, and they talked about sexual fantasizing.

We men are a little bit different in that sense. For example, if we are talking and you bend over and show your behind to me, something instantly happens in my brain. Women do not think like that. [63-year-old man]

Then men were however eager to point out that these feelings of attraction to other women remained at the level of fantasy and that they would never cheat on their partner. There was a general expectation among the interviewees that men tend to be more interested in sex and become aroused more easily than women do:

We men get started sooner. For women, it takes some time to get started up. It won't happen unless I make it happen, because she doesn't initiate. [63-year-old man]

\section{The Silence Surrounding Sexuality Leaves One Alone with Questions About Normality}

All of the interviewees considered sexuality to be a private matter, and they felt this made it difficult to communicate about their experiences of sexual dysfunction and sexual problems. Many worried about whether their feelings and physical reactions were normal and about how their relationship with their partner compared with those of couples in which neither partner suffered from hypopituitarism. Both men and women wondered what their sexuality would have been like if they had not suffered from hypopituitarism and whether the negative changes were induced by the disorder or by normal ageing processes. On the one hand, they claimed their sexual desire and functioning had been altered since receiving their diagnosis. On the other, they wondered whether these things maybe naturally decrease with age. They said they found it difficult to discuss these concerns with other people. They talked of relying on non-verbal communication with their partners, while 
most of the participants had not openly discussed sexual matters with their partner. Men described how, if the topic of sexuality arose in their circle of male friends, it was usually dealt with in a jocular or sometimes vulgar way. One man said he thought it was easier for women to discuss sexual matters with their female friends than for men to talk to other men about these things, although none of the female interviewees confirmed his view:

I do not know if I'm generalizing, but I experience this as a male problem. Women

talk to each other about such things in a way that guys do not. [45-year-old man]

It was also striking that sexuality was apparently not discussed with healthcare professionals, even though the participants said they wanted to. They said they wanted their doctor to introduce the subject and to follow up on how the treatment was affecting their sexuality. In the cases in which a doctor had broached the question, there was a notable difference in how they dealt with it in relation to men and to women. Some of the men we interviewed said their doctors had asked them about erectile functioning, whereas the women of reproductive age had been told they could seek medical assistance if they wanted to become pregnant. Regardless of age, none of the women said they had been asked about their sexual functioning and they felt that their questions about getting help for diminished sexual desire generally went unheard. One woman said she felt abandoned by her doctor, who had offered to let her try a testosterone-patch but seemed skeptical about it and never followed up on it. This woman and her partner had been prepared to try the treatment, but felt that neither the endocrinologist nor the gynecologist wanted to take responsibility, each referring the question to the other and leaving the couple feeling unsupported.

\section{Discussion}

We have described how men and women living with hypopituitarism experience their sexuality. Our study highlights previously neglected factors relating to the patients' own experiences of the relationship between their sexuality and the disorder, and these factors are relevant to their care. The participants' narratives stress how negatively both their sexual functioning and sexual wellbeing are affected.

A significant finding was that although men and women both found their sexuality was altered, healthcare professionals responded differently according to the patient's gender. The women who participated in this study claimed that their sexual concerns and sexual functioning tended to be ignored or not followed up. The men's narratives focused largely on the physical features of sexual functioning and although they were pleased with the improvements they experienced in erectile function and libido following hormonal treatment, they said that little attention was paid to their sexual wellbeing overall. Clearly, the patients' concerns about sexuality extends beyond medical and physical issues and relate to loneliness, loving relationships and self-perception. Although the patients in this study expressed a desire to talk about these matters with their carers, in general, they had spoken neither with their partners nor with health professionals and this left them feeling alone with their distress and feeling isolated. They were often concerned with the question of whether or not their sexuality was normal by comparison with people who do not suffer from hypopituitarism.

In this section, we will discuss the implications of these findings for making improvements to the care these patients receive. We focus on four interlinked factors: (1) normality and normativity in relation to sexuality; (2) the narrow medical focus on men's sexuality; 
3) the marginalization of women's sexuality and (4) the need for healthcare professionals to develop a deeper, reflexive understanding of the complexity of sexuality, including how cultural norms may influence care and dialogue. That more research is needed on the treatment of people suffering from hypopituitarism in general [4], on hormonal treatment in women in particular $[1,8,11]$ and also how this relates to social features of women's sexuality [10] is well recognized. Nevertheless, this study found that researchers are cautious about ascribing positive results to the use of androgens to treat women with hypopituitarism. We suggest that women's experiences of clinicians' ambivalence about hormone replacement for them may be related to this caution that we further understand as related to research interest and cultural perceptions of gender and sexuality. Together with the four factors in patients' experiences of sexuality, this all reinforces female patients' feelings of anxiety and abandonment by their carers. The following subsections develop these themes further.

\section{Normality and Normativity in Relation to Sexuality}

Our interviewees' experiences of sexuality clearly were influenced by their perception of their ability to fulfill current gender norms. This negatively influenced their sexual wellbeing following Cleary's and Hegarty's definition [13]: The effects of hormone deficiency, such as fatigue, lack of initiative and weight gain, caused distress among both men and women in relation to their sense of self and their sexual relationships. This was particularly noticeable in the women's narratives, which stressed the importance of feeling comfortable with one's own body and feeling attractive in order to feel desire for someone else. This finding correlates with comparable qualitative studies of women with fibromyalgia and survivors of breast cancer [33, 34]. Weight gain also impacted negatively on men's self-perception because they related it to reduced physical capacity and sexual stamina.

Significantly, the participants in our study were concerned with whether or not their physical reactions, feelings and relationships were normal compared with people who do not suffer from hypopituitarism. All of the participants, whose ages spanned 37-77 years, were unsure about whether the negative changes they experienced in their sexuality were the result of their disorder or simply part of the normal ageing process.

Contemporary western society places great emphasis on the importance of sexuality and normality and many people are concerned about whether or not their libido and level of sexual activity is normal. British sociologist Jeffrey Weeks [26] notes that sexuality is regarded as part of a person's true, inner self, and that there is a strong relationship between identity and desire. This was echoed in our study. The participants associated sexual desire and being engaged in an active sexual relationship with identity and self-esteem. Wierman et al. [10] indirectly acknowledge today's cultural focus on the importance of sexual desire as proof of normality. They criticize the increasingly common notion that low libido is a medical problem that requires treatment with hormones, and that lack of desire in women in particular is often viewed as a form of sexual dysfunction. They strongly argue against this and refer to a study which shows that a lack of sexual desire is common in healthy women but this does not necessarily imply that they do not experience sexual arousal and satisfaction:

An absence of sexual desire between sexual encounters appears to be common, well within the range of normal female sexual experience/.../Most of the 3,250 multiethnic middle-aged women in the SWAN cohort indicated that while moderately or extremely sexually satisfied, they never or very infrequently felt desire... In an on- 
line survey of 3,687 younger women, 1,865 were assessed to be without evidence of sexual dysfunction, specifically confirming their easy sexual arousal. Close to one third of this group rarely or never began a sexual experience with a sense of sexual desire..." [10, pp. 3503-3504, our emphasis]

This non-causal relationship between desire, arousal and satisfaction is rarely discussed as something normal [10]. The participants in our study, both women and men, were suffering from androgen deficiency and this is known to reduce sexual desire. They wanted to discuss their worries about this with their carers. We suggest that their distress is amplified by prevalent cultural norms that present healthy sexuality as consistently high libido. This cultural climate adds to the distress experienced by the participants in our study. We therefore propose that healthcare professionals should invite their patients to engage in dialogue about their altered sexuality and reduced sexual desire. Important in these discussions is the clinicians' awareness of the way in which contemporary socio-cultural understandings of sexuality and the cultural stress on sexual desire may affect their patients.

\section{A Narrow Medical Focus on Men's Sexuality}

Our findings revealed that current healthcare practices tend to focus on sexual functioning in men although this alone does not provide the all-round care that these patients, men as well as women, require. The direct physiological effects of the condition reported by our study participants were altered libido, impaired erectile functioning and vaginal lubrication, and the ability to experience orgasm. With the help of hormone replacement therapy, which our female interviewees said was estrogen and the men said was testosterone, some said they regained libido. Men who had received hormone replacement therapy described powerful feelings of happiness when their sexual desire and function returned, even if they continued to have some difficulty ejaculating and experiencing orgasm. Quantitative studies have shown that men who are treated with testosterone have more nocturnal erections, sexual thoughts and motivation, higher scores on erectile function and regularity of sexual intercourse, and experience greater sexual satisfaction [35]. The same study showed that abnormal hormone levels have a direct effect on sexual functioning, and this was echoed in the narratives of some of the men in our study who described extreme and also disturbing reactions to the treatment. However, despite experiencing better erectile function and libido, the men also said they felt fatigued and lacked drive and that this hindered them in sexual activities. They wondered whether this was normal by comparison with people who did not suffer from hypopituitarism. In general, the men said they felt their medical care was good though they would have liked more help to improve their sexual wellbeing. Overall, the participants in this study expressed a need for greater attention to be paid to sexual wellbeing, or what Verschuren et al. [12] refers to as a person's experience of sexuality in their daily life and relationships with others, and also sexual self-conception [13].

\section{Women's Sexuality is Marginalized}

By contrast, the women in this study felt that both their sexual concerns and function were overlooked by the healthcare professionals. Few of the women we interviewed even seemed aware of a connection between their diagnosis and reduced libido and the healthcare professionals they met seldom if ever talked to them about it. This meant that few of them had been offered any treatment for it. Women who had received estrogen treatment 
described improvements in vaginal lubrification. One woman was consequently hesitant to stop taking estrogen even though her doctor recommended this due to her age - she was afraid that it would reduce her libido. The difference in the way women and men spoke about their responses to hormone treatment is significant. The women who had received estrogen spoke somewhat vaguely of positive effects while the men described the effects of testosterone in more dramatic terms, using words such as 'bliss' and 'happiness', though they also mentioned feeling an unpleasant loss of control.

Some of those women who had asked for help with improving sexual desire said they did not receive any. One woman said she felt abandoned by the clinicians and was left feeling confused by her doctor's ambivalent attitude in suggesting testosterone treatment but never following this up, despite the fact that both she and her partner wanted to give it a try. She also said that the gynecologist and endocrinologist had each referred her to the other for help. Women's sexual function, (i.e. desire, arousal/vaginal lubrication and ability to reach orgasm) was not generally given as much consideration as was men's sexual functioning. We know that women with hypopituitarism suffer from severe androgen deficiency [3] and that these women may need androgen supplementation in addition to estrogen [4]. There is some evidence that androgens positively influence "all aspects of sexual response by improving desire, subjective arousal, and vaginal blood flow ... and increasing frequency of orgasm" in postmenopausal women who report low sexual desire [10, p. 3499]. Some studies of women with hypopituitarism have shown positive effects of androgen replacement on libido, mood and sexual function [11], sexual interest, activity and sexual relations with partners [8]. Unfortunately however, testosterone treatment does not always work well for women because of undesirable side effects, such as increased perspiration, acne and undesired hair growth [36]. Current guidelines recommend against routine use of androgen replacement in women with hypopituitarism due to limited knowledge of its effects and long-term safety [10]. The existing research on androgen replacement has largely been conducted on men. Few preparations have been tested on women and still fewer have been accepted for use [1, 14]. Although androgen replacement in women with hypopituitarism, is associated, as noted with androgenic effects on the skin, hair and sweating and some women see this as a barrier to accepting treatment $[8,11]$, there are nevertheless some promising results. Researchers are unanimous that more research is needed to find out what sort of androgens and what doses could be recommended for individual women $[4,8,37,38]$. In sum, it is clear that the consequences of androgen deficiency in women and replacement with androgens in women with hypopituitarism requires further investigation.

On the cultural level, we suggest that the different degrees of medical interest given to women's and men's sexual function found in our study reflects core cultural values concerning gender and sexuality, according to which men are cast as being more interested in sex while women are more concerned about relationships [23]. Historically, in Europe, female sexuality has been viewed as passive and weak, while men's is active and dominant [19-21, 23, 39, 40]. Some of the participants in this study reproduced these norms in what they said. Anthropological studies of biomedicine describe how hospitals, as social institutions, exhibit core cultural values and beliefs, and "both reflect and reinforce dominant social and cultural processes of a given society" [41, p. 1996]. Much contemporary psychology also perpetuates the idea that "men want sex while women want relationships" $[40$, p. 3]. We propose that the general cultural perception of women as having a weaker sexuality than men unintentionally but negatively influences research interest and also the ability of healthcare professionals to capture or elicit women's sexual concerns about their sexuality. 


\section{Healthcare Professionals Need Time to Reflect, Build Knowledge and Engage in Dialogue}

The participants in this study expressed feelings of loneliness since they felt they could not talk with their partner, friends or carers about their experiences of their sexuality. They said they wanted to discuss their experiences of negative changes in their sexuality with the healthcare professionals so as to find out whether these were related to their diagnosis or were normal features of the ageing process. The men also said they wanted to talk to their doctors about more than just their sexual functioning, but about sexual wellbeing as well. The psychological wellbeing of people suffering from chronic illness has been shown to depend upon their ability to adapt to and cope with the changes it implies-and this ability is affected by the chances they have to talk to someone about what is happening to them [12]. Yet, the general silence on the issue of sexuality made it difficult for them to engage in conversation about it. This problem is not unique to this patient group. Other patient groups have also reported a lack of psychosexual information and support, and a focus on medically oriented information and support [42]. The focus in healthcare on sexual functioning contrasts sharply with the multiple meanings that our participants awarded to sexuality. In society in general, the topic of sexuality is rarely treated as suitable for public discussion but is instead considered to be a private matter [23]. For this reason, patients' sexuality is often neglected [43], and people with disabilities are often left to manage their sexuality by themselves despite needing support [27]. Some studies have found that nurses find they have no time to raise these issues and that patients are often reticent about discussing their sex lives with nurses [44, 45]. Ho \& Fernandez [46] explored the role played by healthcare professionals in meeting patients' needs for dialogue about sexual issues. Although the staff rated the importance of the patients' sexual health as important, the majority (86\%) of them said they did not pay enough attention to sexual issues in their encounters with patients, and a full $92 \%$ of them said that they never initiate discussions about sexuality with patients.

Sexual wellbeing is a central feature of a person's dignity and is a matter of human rights and social justice [27, 47]. It is the responsibility of healthcare professionals to initiate and maintain dialogue about sexuality in response to their patients' needs [14]. Studies have shown that nurses who have experience and specialist training are more likely to raise questions about sexuality [43]. Training and experience thus make a difference. Healthcare professionals therefore clearly require time and space for reflection so that they are able to see beyond normative understandings of sexuality and play a supportive role in initiating dialogue with patients about it. Importantly, the healthcare staff, particularly doctors, ought to explain to female patients that there is scanty research on the effects of using androgenes to treat women, but that a few studies conducted have given positive results. Patients have a right to know this in order to be able to participate in their care and take informed decisions, to be partners in care [48]. The healthcare providing organization should schedule time for the staff to learn about the complexity of sexuality, and it should promote multiprofessional teamwork that includes specialists on sexuality from other caring professions [14]. Therefore, it is important that healthcare management staff are engaged in improving care for people suffering from hypopituitarism. 


\section{Limitations and Strengths}

This study explores how people with hypopituitarism experience their sexuality in relation to their diagnosis and treatment. One of the study's strengths is the fact that the research group included three healthcare professionals, two RNs (JPT, ACO) and one physician (GJ) who had been caring for people with hypopituitarism for a long time. GJ also has many years of experience as a researcher in this field. The group also included a professor in healthcare sciences (EJU), and two gender researchers (IB, LD), one of whom is a social anthropologist (LD) with expertise in culture and sexuality $[49,50]$. Detailed, ongoing discussions during the research process between these co-authors, with their many different perspectives, mitigated against a bias towards one particular viewpoint. However, the study also had limitations. For instance, the participants varied in age, hormonal status and symptom profile. This may be regarded as both a strength and a weakness: It could be argued that the sexuality of pre- and post-menopausal women cannot be compared, although we found no clear differences between pre-and postmenopausal women's experiences of their sexuality. All of the participants identified themselves as heterosexual, which excludes other possible experiences of sexuality. However, it is difficult to know whether this reflected the silencing of other sexual identities and desires by the power of heteronormativity [18] or whether it was an accurate representation of the interviewees experiences. Due to the impact of culture on sexuality, the findings might not be transferable to other cultural contexts. Nevertheless, since the biomedical perspective, with its focus on bodily functioning, is global, the study may serve as a base for reflection for healthcare professionals the world over. The interviews that were analysed in this study were conducted seven years ago. While norms relating to sexuality change over time, they do so slowly and the researchers on our team who have continued working clinically with this patient group since then have noted no developments in healthcare in relation to questions on sexuality. This means our data remain valid and appropriate to the present-day context.

\section{Conclusions}

The association between chronic disease and sexuality is complex since it taps into issues beyond sexual functioning, such as sexual wellbeing, intimate relationships, self-perception and gendered cultural norms. Current healthcare practices tend to focus on erectile function for men, which fails to meet their need of more holistic care, and to silence women's sexuality altogether. Those caring for people with hypopituitarism may unwittingly reproduce normative understandings of sexuality in the care they provide. On the one hand, they may marginalize women's sexuality and on the other, fail to meet men's needs for help with their sexual concerns beyond the 'performance standards' of erection and libido. In order to ensure equity in the care of people suffering from hypopituitarism, healthcare therefore needs to broaden its perspective from the medical focus on sexual function alone to include sexual wellbeing and an understanding of the norms governing gender and sexuality.

Acknowledgements Open access funding provided by University of Gothenburg. We would like to express our gratitude to the participants in this study for generously sharing their experiences.

Funding The study was financed by grants from the Swedish state under the agreement between the Swedish government and the country councils, the ALF-agreement (ALFGBG-719531). 


\section{Compliance with Ethical Standards}

Conflict of interests The authors declared no potential competing interests with respect to the research, authorship or publication of this article.

Open Access This article is licensed under a Creative Commons Attribution 4.0 International License, which permits use, sharing, adaptation, distribution and reproduction in any medium or format, as long as you give appropriate credit to the original author(s) and the source, provide a link to the Creative Commons licence, and indicate if changes were made. The images or other third party material in this article are included in the article's Creative Commons licence, unless indicated otherwise in a credit line to the material. If material is not included in the article's Creative Commons licence and your intended use is not permitted by statutory regulation or exceeds the permitted use, you will need to obtain permission directly from the copyright holder. To view a copy of this licence, visit http://creativecommons.org/licenses/by/4.0/.

\section{References}

1. Legato, M.: Eves's Rib. The New Science of Gender-Specific Medicine and How it can Save Your Life. Harmony Books, New York (2002)

2. Fausto-Sterling, A.: Sexing the Body. Gender Politics and the Construction of Sexuality. Basic Books, New York (2000)

3. Miller, K., Sesmilo, G., Schiller, A., Schoenfeld, D., Burton, S., Klibanski, A.: Androgen deficiency in women with hypopituitarism. J. Clin. Endocrinol. Metab. 86(2), 561-567 (2001)

4. Higham, C., Johannsson, G., Shalet, S.: Hypopituitarism. The Lancet 388(10058), 2403-2415 (2016). https://doi.org/10.1016/S0140-6736(16)30053-8

5. Burger, H.G., Papalia, M.A.: A clinical update on female androgen insufficiency- testosterone testing and treatment in women presenting with low sexual desire. Sex Health 3(2), 73-78 (2006)

6. Koltowska-Häggström, M., Mattsson, A., Monson, J., Kind, P., Badia, X., Casanueva, F., Johannsson, G.: Does long-term GH replacement therapy in hypopituitary adults with GH deficiency normalise quality of life? Eur. J. Endocrinol. 155(1), 109-119 (2006). https://doi.org/10.1530/ eje. 1.02176

7. Olsson, S.D., Nilsson, G.A., Bryngelsson, G.I.-L., Trimpou, G.P., Johannsson, G.G., Andersson, G.E.: Excess mortality in women and young adults with nonfunctioning pituitary Adenoma: a Swedish nationwide study. J. Clin. Endocrinol. Metab. 100(7), 2651-2658 (2015). https://doi. org/10.1210/jc.2015-1475

8. Johannsson, G., Burman, P., Wiren, L., Engstrom, B.E., Nilsson, A.G., Ottosson, M., Karlsson, F.A.: Low dose dehydroepiandrosterone affects behavior in hypopituitary androgen-deficient women: a placebo-controlled trial. J. Clin. Endocrinol. Metab. 87(5), 2046-2052 (2002). https:// doi.org/10.1210/jcem.87.5.8494

9. Wirén, L., Boguszewski, C.L., Johannsson, G.: Growth hormone (GH) replacement therapy in GHdeficient women during pregnancy. Clin. Endocrinol. (Oxf) 2002(57), 235-239 (2002)

10. Wierman, M.E., Arlt, W., Basson, R., Davis, S.R., Miller, K.K., Murad, M.H., Rosner, W., Santoro, N.: Androgen therapy in women: a reappraisal: an Endocrine Society clinical practice guideline. J. Clin. Endocrinol. Metab. 99(10), 3489-3510 (2014). https://doi.org/10.1210/jc.2014-2260

11. Miller, K., Biller, M., Beauregard, G., Lipman, C., Jones, C., Schoenfeld, C., Klibanski, C.: Effects of testosterone replacement in androgen-deficient women with hypopituitarism: a randomized, double-blind, placebo-controlled study. J. Clin. Endocrinol. Metab. 91(5), 1683-1690 (2006). https:// doi.org/10.1210/jc.2005-2596

12. Verschuren, J.E.A., Enzlin, P., Dijkstra, P.U., Geertzen, J.H.B., Dekker, R.: Chronic disease and sexuality: a generic conceptual framework. J. Sex Res. 47(2-3), 153-170 (2010). https://doi. org/10.1080/00224491003658227

13. Cleary, V., Hegarty, J.: Understanding sexuality in women with gynaecological cancer. Eur. J. Oncol. Nurs. 15(1), 38 (2011)

14. Hulter, B.: Sexualitet och hälsa: begränsningar och möjligheter [Sexuality and Health: Limitations and Possibilities]. Studentlitteratur, Lund (2004)

15. World Health Organization: Sexual and reproductive health. WHO, Geneva (2006) 
16. Helmius, G.: Sociosexuell utveckling i ungdomsåren: [Sociosexual development in youth]. In: Lundberg, P.O., Löfgren-Mårtenson, L. (eds.) Sexologi [Sexology]. Stockholm, Liber (2010)

17. Löfgren-Mårtenson, L.: Sexualitet [Sexuality]. Liber, Stockholm (2013)

18. Butler, J.: Gender trouble: feminism and the subversion of identity. New York: Routledge (2006[1999])

19. Johannisson, K.: Den mörka kontinenten: kvinnan, medicinen och fin-de-siècle [The dark continent: women, medicine and fin-de-siècle], 2nd edn. Norstedt, Stockholm (2005)

20. Rubin, G.: Thinking sex: Notes for a radical theory of the politics of sexuality. In: Vance, C.S. (ed.) Pleasure and danger: exploring female sexuality. Routledge \& Kegan Paul, Boston (1984)

21. Rubin, G.: Thinking sex: Notes for a radical theory of the politics of sexuality. In: Parker, R., Aggleton, P. (eds.) Culture, society and sexuality: A reader, pp. 143-178. Routledge, Oxon and New York (2007)

22. McRuer, R.: Crip theory: cultural signs of queerness and disability. New York University Press, New York (2006)

23. Giddens, A.: Intimitetens omvandling: sexualitet, kärlek och erotik i det moderna samhället [The transformation of intimacy]. Nya Doxa, Nora (1995)

24. Caplan, P.: The cultural construction of sexuality. Routledge, London (1987)

25. Foucault, M.: The history of sexuality. The will to knowledge, vol. 1. Penguin, Harmondsworth (1990)

26. Weeks, J.: Sexuality. Routledge, London (1986)

27. Kulick, D., Rydström, J.: Loneliness and Its Opposite: Sex, Disability, and the Ethics of Engagement. Duke University Press, Durham (2015)

28. Fleming, V., Gaidys, U., Robb, Y.: Hermeneutic research in nursing: developing a Gadamerian-based research method. Nursing Inquiry 10(2), 113-120 (2003). https://doi.org/10.104 6/j.1440-1800.2003.00163.x

29. Gadamer, H.-G.: Truth and Method. Sheed and Ward, London (1989)

30. Scott-Jones, J., Watt, S. (eds.): Ethnography in Social Science Practice. Routledge, New York (2020)

31. Skott, C.: Skrivandets process (The process of writing). In: Skott, C., Dellenborg, L., Lepp, M., Nässén, K. (eds.) Människan i vården. Etnografi, vård och drama (People in health care. Ethnography, care and drama). Carlssons förlag, Stockholm (2013)

32. Whittemore, R., Chase, S., Mandle, C.L.: Validity in qualitative research. Qual. Health Res. 11(4), 522-537 (2001). https://doi.org/10.1177/104973201129119299

33. Matarín Jiménez, T.M., Fernández-Sola, C., Hernández-Padilla, J.M., Correa Casado, M., Antequera Raynal, L.H., Granero-Molina, J.: Perceptions about the sexuality of women with fibromyalgia syndrome: a phenomenological study. J. Adv. Nurs. 73(7), 1646-1656 (2017). https://doi. org/10.1111/jan. 13262

34. Wilmoth, M.C.P.R.N.: The aftermath of breast cancer: an altered sexual self. Cancer Nurs. 24(4), 278-286 (2001)

35. Isidori, A., Giannetta, E., Gianfrilli, D., Greco, E., Bonifacio, V., Aversa, A., Lenzi, A.: Effects of testosterone on sexual function in men: results of a meta-analysis. Clin. Endocrinol. 63(4), 381-394 (2005). https://doi.org/10.1111/j.1365-2265.2005.02350.x

36. Davis, S.R.: Androgens and female sexuality. J. Gender-Spec. Med. 3, 36 (2000)

37. Clayton, P.E., Cuneo, R.C., Juul, A., Monson, J.P., Shalet, S.M., Tauber, M.: Consensus statement on the management of the GH-treated adolescent in the transition to adult care. Eur. J. Endocrinol. 152(2), 165-170 (2005)

38. Ho, K.K.Y.: Consensus guidelines for the diagnosis and treatment of adults with GH deficiency II: a statement of the GH Research Society in association with the European Society for Pediatric Endocrinology, Lawson Wilkins Society, European Society of Endocrinology, Japan Endocrine Society, and Endocrine Society of Australia. Eur. J. Endocrinol. 157, 695-700 (2007)

39. Connell, R.: Gender in World Perspective. Polity, Cambridge (2009)

40. Laqueur, T.: Making Sex: Body and Gender from the Greeks to Freud. Harvard University Press, Cambridge (1990)

41. van der Geest, S., Finkler, K.: Hospital ethnography: introduction. Soc. Sci. Med. 59, 1995-2001 (2004)

42. Vermeer, W.M., Bakker, R.M., Kenter, G.G., Stiggelbout, A.M., ter Kuile, M.M.: Cervical cancer survivors and partners; experiences with sexual dysfunction and psychosexual support. Support. Care Cancer 24(4), 1679 (2016). https://doi.org/10.1007/s00520-015-2925-0 
43. Saunamaki, N., Andersson, M., Engstrom, M.: Discussing sexuality with patients: nurses' attitudes and beliefs. J. Adv. Nurs. 66(6), 1308-1316 (2016). https://doi.org/10.111 1/j.1365-2648.2010.05260.x

44. Julien, J.O., Thom, B., Kline, N.E.: Identification of barriers to sexual health assessment in oncology nursing practice. Oncol. Nurs. Forum 37(3), E186-E190 (2010). https://doi.org/10.1188/10. onf.e186-e190

45. Magnan, M.A., Reynolds, K.: Barriers to addressing patient sexuality concerns across five areas of specialization. Clin Nurse Spec 20(6), 285-292 (2006)

46. Ho, T.M., Fernandez, M.: Patient's sexual health: do we care enough? J Ren Care 32(4), 183-186 (2006)

47. Nussbaum, M.C.: Capabilities as fundamental entitlements: sen and social justice. Feminist economics 9(2/3), 33-59 (2003)

48. Ekman, I., Swedberg, K., Taft, C., Lindseth, A., Norberg, A., Brink, E., et al.: Person-centered care: ready for prime time. Eur. J. Cardiovasc. Nurs. 10(4), 248-251 (2011)

49. Dellenborg, L.: A reflection on the cultural meanings of female circumcision. Experiences from fieldwork in Casamance, Senegal. In: Arnfred, S. (ed.) Re-thinking Sexualities in Africa. Nordiska Afrikainstitutet, Uppsala (2004)

50. Dellenborg, L.: Multiple meanings of female initiation. 'Circumcision' among Jola women in Lower Casamance, Senegal. Unpublished PhD dissertation. School of Global Studies, University of Gothenburg. (2007)

Publisher's Note Springer Nature remains neutral with regard to jurisdictional claims in published maps and institutional affiliations.

\section{Affiliations}

\section{Lisen Dellenborg ${ }^{1,2}$ (D) Jenny Tiberg Persson ${ }^{3} \cdot$ Eva Jakobsson Ung $^{1,2,3}$. Gudmundur Johannsson ${ }^{3,4}$. Ann-Charlotte Olofsson ${ }^{1,3} \cdot$ Ida Björkman $^{1,2}$}

Jenny Tiberg Persson

jenny.c.tiberg@vgregion.se

Eva Jakobsson Ung

eva.jakobsson@fhs.gu.se

Gudmundur Johannsson

gudmundur.johannsson@medic.gu.se

Ann-Charlotte Olofsson

ann-charlotte.olofsson@vgregion.se

Ida Björkman

ida.bjorkman@gu.se

1 Institute of Health and Care Sciences, The Sahlgrenska Academy, University of Gothenburg, Box 457, 40530 Gothenburg, Sweden

2 Centre for Person-Centred Care (GPCC), Institute of Health and Care Sciences, The Sahlgrenska Academy, University of Gothenburg, Gothenburg, Sweden

3 Department of Medicine, Region Västra Götaland, Sahlgrenska University Hospital, Gothenburg, Sweden

4 Department of Internal Medicine and Clinical Nutrition, Institute of Medicine, Sahlgrenska Academy, University of Gothenburg, Gothenburg, Sweden 